\title{
Polyploidy and clonal diversity in an arctic cladoceran
}

\author{
FRANCE DUFRESNE* \& PAUL D. N. HEBERT \\ Department of Zoology, University of Guelph, Guelph, Ontario, Canada N1G 2W1
}

\begin{abstract}
Genome size determinations were coupled with allozyme and mtDNA studies to gain insights into the origin of polyploidy and clonal diversity in populations of Daphnia tenebrosa from Churchill, Manitoba. Allozymic variation at five enzyme loci allowed the detection of 32 clones. Analyses of 73 populations in 1981, 27 in 1987 and 45 in 1991 revealed that clonal frequencies were relatively stable and that $D$. tenebrosa was more clonally diverse (average of three clones per pond) than other species of the $D$. pulex complex at the same site. Genome size determinations revealed the presence of two clonal assemblages with averages of $0.53( \pm 0.01) \mathrm{pg}$ and $0.89( \pm 0.03) \mathrm{pg}$, corresponding to diploid and tetraploid clones. Clustering of allozyme distances revealed three groups, with no association between ploidy level or pigmentation. Similarly, diploid and polyploid clones did not form distinct clusters on the mtDNA dendrogram. The high sequence divergence between the two mtDNA clusters as well as the lack of correspondence between allozyme distance and mtDNA divergence among clonal pairs both suggest that polyploidy arose following reciprocal hybridizations between genetically divergent populations of this species.
\end{abstract}

Keywords: allozymes, arctic habitat, clonal diversity, Daphnia, mtDNA, polyploidy.

\section{Introduction}

Many asexual taxa are clonally diverse, physiologically differentiated and have wider distributions than their bisexual relatives (Parker, 1979; Bierzychudek, 1985; Ellstrand \& Roose, 1987; Weider \& Hebert, 1987a; Beaton \& Hebert, 1988; Christensen et al., 1988; Wilson \& Hebert, 1992; Zhang \& Lefcort, 1992). Also, the vast majority of apomictic lineages are polyploid, which has led to the suggestion that polyploidy is of adaptive significance to asexual organisms (Mogie, 1986). Indeed, the combination of two or more divergent genomes often leads to high heterozygosity levels in polyploids, which may endow them with novel ecological tolerance (Lewis, 1980) and explain their wider distribution (Bierzychudek, 1985). Polyploidy has been reported in at least six invertebrate phyla (Bell, 1982), but few of these groups have been the objects of detailed studies on the origin and maintenance of genetic diversity.

Members of the Daphnia pulex complex are among the best studied obligate parthenogens. Temperate populations of this complex reproduce by cyclic or obligate parthenogenesis (Hebert et al.,1993), and are

*Correspondence. invariably diploid. Arctic populations have completely abandoned sexual reproduction and include numerous polyploid clones (Beaton \& Hebert 1988; Ward et al., 1994). Allozyme analyses have shown that clonal diversity is very high in these obligate parthenogens with thousands of clones occurring over the species distribution. However, single habitats typically contain fewer than three clones in both temperate and lowarctic sites (Hebert \& Crease, 1983; Weider \& Hebert, 1987a; Hebert et al., 1989; Wilson \& Hebert, 1992). Higher levels of clonal diversity (an average of 4.5 clones per pond) have been found at a high-arctic site occupied almost exclusively by polyploid clones (Weider et al., 1987). Joint allozyme and mtDNA evidence suggests that the high diversity seen in asexual populations from the temperate zone arises from the polyphyletic origins of asexuality (Crease et al., 1989).

Sites in arctic Canada provide an opportunity to study patterns of clonal diversity in undisturbed habitats. Particularly intensive genetic analysis has been conducted on the daphniid fauna of ponds near Churchill, Manitoba. Prior allozyme and mtDNA studies have established the presence of three divergent assemblages of the $D$. pulex group at this locality. The two most closely related of these groups, which have been regarded as forms of $D$. pulex, are 
allozymically similar but differ in cuticular pigmentation, ploidy level and mitochondrial genomes. Members of the melanic assemblage, which includes at least 16 allozymically distinct clones (Weider \& Hebert, 1987a), are invariably polyploid and appear to have arisen from hybridization between species in the pulex complex (Dufresne \& Hebert, 1994). The second assemblage includes at least 35 diploid clones (Wilson \& Hebert, 1992) all of which lack pigmentation and show both mitochondrial and allozymic convergence to temperate zone populations of $D$. pulex. Much less work has been done on the third assemblage, although it is known to be clonally diverse (Hebert \& McWalter, 1983) and to show variation in both pigmentation intensity and genome size (Hebert, 1987). Because of its marked genetic divergence from the other members of the pulex complex, this assemblage is regarded as a distinct taxon (D. tenebrosa).

This study aims to provide a more detailed understanding of genetic diversity in $D$. tenebrosa. Allozyme analysis was carried out over a 10-year period to ascertain both the extent of clonal diversity and the stability of clonal arrays in a large number of habitats. Studies of genome size were subsequently coupled with allozyme studies to ascertain the ploidy levels of individual clones. Finally the extent of mtDNA divergence among clones was appraised to examine the role of hybridization in the generation of clonal and ploidy level variation.

\section{Materials and methods}

\section{Taxonomic assignments}

Tundra ponds in the Holarctic are dominated by obligately asexual members of the Daphnia pulex group. In Eurasia these species have been assigned to two different taxa: $D$. middendorffiana and $D$. tenebrosa. Both of these species share a melanized cuticle, but $D$. tenebrosa has a longer tail spine and a more reduced head. Brooks (1957) assigned all obligately asexual lineages of Daphnia in arctic North America to $D$. middendorffiana. Allozyme studies (Hebert \& McWalter, 1983) later showed that there were two genetically divergent groups, which were identified as $D$. pulex and $D$. middendorffiana. Joint morphological and genome size studies subsequently showed that $D$. pulex could be further subdivided into unpigmented diploid forms and polyploids with melanized cuticles (Beaton \& Hebert, 1988). Mitochondrial analysis (Stanton, 1988; Dufresne \& Hebert, 1994; Van Raay \& Crease, 1995) later showed that the polyploids and diploids were genetically distinctive, supporting their recognition as separate taxa. In this paper we retain the classification of the diploid unpigmented forms as $D$. pulex, but now assign melanic polyploid clones to $D$. middendorffiana because of their close morphological resemblance to Eurasian populations of this species. Finally, we reassign those populations previously identified as $D$. middendorffiana to $D$. tenebrosa because of their morphological similarity to that species (Fig. 1).

\section{Sampling}

Populations of D. tenebrosa were collected from tundra ponds near Churchill, Manitoba, in July/August of 1981, 1987, 1991 and 1992. One hundred ponds, situated near the road from Akudlik to the Churchill launch facility, were collected in 1981. Seventy-three of these habitats contained sufficient individuals of $D$. tenebrosa for genetic characterization. Twenty-seven of these populations were reanalysed in 1987 whereas 45 populations were recollected in 1991 to ascertain the stability of clonal frequencies. Additional clones were collected in 1992 for mtDNA analyses. Following their collection, animals were either stored in liquid nitrogen or analysed immediately.

\section{Electrophoresis}

Electrophoresis was performed on acrylamide gels in 1981 and on cellulose acetate gels in 1987, 1991 and 1992, following standard methods (Hebert \& Beaton, 1989). Each individual was examined for variation at 10 enzyme loci: aldehyde oxidase (AO, EC 1.2.3.1), amylase (AMY, EC 3.2.1.1), fumarate hydratase (FUM, EC 4.2.1.2), glutamate-oxaloacetate transferase (GOT, EC 2.6.1.1), lactate dehydrogenase (LDH, EC 1.1.1.27), malate dehydrogenase ( $\mathrm{MDH}$, EC 1.1.1.37), malate dehydrogenase (ME, EC 1.1.1.40), mannose-6-phosphate isomerase (MPI, EC 5.3.1.8), phosphoglucose isomerase (PGI, EC 5.3.1.9) and phosphoglucomutase (PGM, EC 5.4.2.2). Estimates of

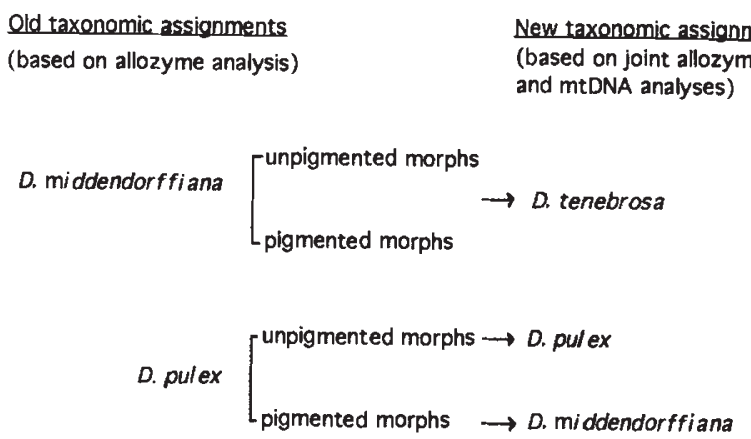

Fig. 1 Taxonomic reassignments of arctic taxa of the Daphnia pulex complex from Churchill, Manitoba. 
genetic identity (Nei, 1978) were calculated among clones for which genome size determinations were also carried out (see below) and were clustered by the unweighted pair-group algorithm (UPGMA) in BIOSYS-1 (Swofford \& Selander, 1989). Data for the genetic distance determinations were entered as allele frequencies. Unbalanced phenotypes were taken into account by adjusting the allele frequencies to reflect those which were present in higher copy number. Hence, in an individual with the phenotype $2 * 34$, allele 2 was assigned a frequency of 0.50 whereas alleles 3 and 4 were each assigned a frequency of 0.25 .

The relationship between number of clones detected as a function of sampling effort was estimated using a BASIC program written by $\mathrm{M}$. Beaton at the University of Guelph. One hundred iterations were performed for each level of sampling intensity (one pond, two ponds, three ponds, ..., etc.).

Clonal stability for the 3 years was estimated using Renkonen's stability index (Krebs, 1989). Only ponds sampled in 1981, 1987, and 1991 were included in this analysis.

\section{Genome size determinations}

In 1987 , a study was carried out to examine the extent of genome size variation among clones of $D$. tenebrosa. Joint allozyme and genome size determinations were made on each of 160 individuals from 27 ponds. The multilocus genotype of each individual was obtained by using its head for allozyme analysis whereas the rest of the animal was fixed in a 3:1 methanol:glacial acetic acid for genome size determination. The genome size of each individual was inferred from determinations of the optical densities (OD) of at least 10 Feulgen-stained nuclei in the exopodites of the third and fourth thoracic limbs using scanning microdensitometry, as described by Beaton \& Hebert (1989). A diploid clone of $D$. pulex from Windsor, Ontario, with a genome size of $0.37 \mathrm{pg}$ was used as an internal standard in each staining run. The genome size of each individual of $D$. tenebrosa was calculated by dividing the mean OD value of its nuclei by the mean $O D$ value for nuclei from the standard clone and multiplying this quotient by 0.37 . In total, genome sizes were determined for 18 clones.

\section{MtDNA analysis}

In 1992 joint information on allozyme and mitochondrial genotypes was obtained through the use of a similar analytical strategy. The head of each individual was used to ascertain its allozyme genotype at the five loci required for clonal discrimination whereas the remainder of its body was used for DNA extraction.
Total DNA was obtained from individuals of 16 different clones using the nucleic acid extraction kit from Microprobe. A $2000 \mathrm{bp}$ segment of the mitochondrial ND4-ND5 genes was subsequently amplified using a standard protocol (Taylor \& Hebert, 1993). Aliquots of this PCR product were digested with 10 restriction endonucleases (HaelII, RsaI, CfoI, MboI, HpaII, TaqI, AluI, DdeI, HinfI, and Sau96I). The digests were run on 2 per cent agarose gels at 90 volts and subsequently stained with ethidium bromide and photographed under UV light. Fragment sizes larger than $60 \mathrm{bp}$ could be detected and their size was estimated by comparison with a $1 \mathrm{~kb}$ ladder. Overall percentage distances of shared restriction sites for each pair of haplotypes were calculated following the Nei \& Tajima (1983) algorithm in REAP (McElroy et al.,1991). The matrix of estimated distances was clustered by UPGMA (Sneath \& Sokal, 1973) using the NEIGHBOR program of PHYLIP, version $3.5 \mathrm{c}$ (Felsenstein, 1993).

\section{Results}

\section{Allozymes and clonal diversity}

Analysis of 5619 individuals over the 10-year interval (3228 in 1981, 1220 in 1987 and 1171 in 1991) led to the detection of 32 clones with five polymorphic loci (Table 1). Fifty-three per cent of the clones showed unbalanced staining activity at one or more loci, suggesting that they were polyploid.

Ponds contained an average of 2.9 clones over the sampling interval. Whereas most habitats contained fewer than three clones, up to nine were found in one pond (Table 2). Clone 1 was dominant, being found in 78 per cent of the ponds and comprising 50 per cent of the individuals sampled (Fig. 2). Seven other clones $(2$, $4,5,8,10,12$ and 13 ) were relatively common, but the majority of clones were infrequent, only being found in single ponds.

The relationship between the number of clones detected as a function of sampling effort revealed that for a given number of ponds, more clones were detected in 1987 than in 1991 or 1981 (Fig. 3). The average number of clones found in single ponds was subsequently recalculated using only ponds that had been sampled in 1981, 1987 and 1991 for a more accurate comparison. Results still revealed a higher clonal diversity in 1987 . The 1981 curve approached an asymptotic level indicating that much of the clonal diversity had been detected by our sampling effort. This was not the case for 1987 and 1991 where a higher sampling intensity could have revealed additional rare clones. Results of the Renkonen's test indicated a high similarity ( 87.5 per cent) in clonal frequencies between 1987 and 1991 but a lower 
Table 1 Allozyme genotypes for clones of Daphnia tenebros $a$ at five enzyme loci and percentage of ponds in which each clone was detected

\begin{tabular}{|c|c|c|c|c|c|c|c|c|}
\hline \multirow[b]{2}{*}{ Clone } & \multicolumn{5}{|c|}{ Enzyme loci } & \multicolumn{3}{|c|}{$\%$ Occurrence } \\
\hline & $P g i$ & $P g m$ & Ao & Got & Fum & 1981 & 1987 & 1991 \\
\hline 1 & $46^{*}$ & $23^{*}$ & 33 & 22 & 11 & 73 & 78 & 84 \\
\hline 2 & 44 & 33 & 33 & 22 & 22 & 40 & 7 & 9 \\
\hline 3 & 44 & $23^{*}$ & 12 & 22 & 11 & 8 & 4 & 2 \\
\hline 4 & 44 & 33 & 33 & 22 & 11 & 36 & 4 & 2 \\
\hline 5 & 44 & $34^{*}$ & 22 & 23 & 22 & 48 & 11 & 7 \\
\hline 6 & 44 & 33 & 22 & 22 & 12 & 12 & 4 & - \\
\hline 7 & 44 & 22 & 33 & 22 & 12 & 1 & - & 15 \\
\hline 8 & 55 & 35 & 33 & 22 & 12 & 3 & 26 & 13 \\
\hline 9 & 44 & $3 * 5$ & $12^{*}$ & 22 & 11 & - & 15 & 6 \\
\hline 10 & $3 * 4$ & 12 & 33 & 22 & 11 & 20 & 33 & 6 \\
\hline 12 & 56 & 22 & 33 & 22 & 12 & 1 & 37 & 13 \\
\hline 13 & 44 & 45 & 13 & 13 & 12 & - & 33 & 28 \\
\hline 16 & 44 & 24 & 22 & 22 & 12 & - & - & 2 \\
\hline 18 & 56 & 35 & 22 & 22 & 12 & - & - & - \\
\hline 20 & 11 & 22 & - & - & - & 1 & - & - \\
\hline 22 & 45 & $345^{*}$ & 12 & 22 & 22 & - & 11 & 2 \\
\hline 23 & $34^{*}$ & 234 & 22 & 22 & 12 & - & 15 & 4 \\
\hline 24 & $3 * 4$ & 134 & 23 & 22 & - & - & - & - \\
\hline 25 & $34^{*}$ & 22 & 33 & 22 & 22 & 1 & - & - \\
\hline 26 & $34^{*}$ & $2 * 3$ & 33 & 22 & 12 & - & 7 & 4 \\
\hline 29 & $45^{*}$ & 23 & 34 & 22 & 12 & - & 7 & 6 \\
\hline 30 & $14^{*}$ & 12 & 33 & 22 & - & 1 & - & - \\
\hline 31 & 44 & $34^{*}$ & 22 & 22 & 22 & 1 & - & - \\
\hline 32 & 44 & $124 *$ & 22 & 23 & 22 & 1 & 11 & - \\
\hline 33 & 44 & 33 & 12 & 22 & 11 & 1 & - & 2 \\
\hline 34 & 44 & 22 & 13 & 22 & 12 & - & 15 & - \\
\hline 35 & $35^{*}$ & $2 * 34$ & 33 & 22 & 12 & - & - & 2 \\
\hline 36 & 22 & 44 & 22 & 23 & 12 & - & 4 & 2 \\
\hline 37 & $3 * 4$ & $234^{*}$ & 22 & 22 & 12 & - & 4 & - \\
\hline 38 & $46^{*}$ & $45^{*}$ & 22 & 22 & 12 & - & 4 & 4 \\
\hline 40 & 24 & 23 & 22 & - & 12 & - & 4 & 2 \\
\hline 41 & 44 & $33^{*}$ & 33 & 22 & 12 & - & - & 2 \\
\hline
\end{tabular}

*Refers to unbalanced heterozygotes. Bold print indicates clones that were discovered in 1992 only.

similarity (64.3 per cent) between 1981 and 1991 . An intermediate value ( 77.5 per cent) was found between 1981 and 1987.

\section{Genome size variation}

The frequency histogram of genome sizes for the 18 clones showed a bimodal distribution (Fig. 4). Clones in the lower distribution had a considerably smaller average genome size of $(0.53 \pm 0.01) \mathrm{pg}$ than clones in the upper distribution $(0.89 \pm 0.03) \mathrm{pg}$. Clones with a genome size ranging from 0.40 to $0.60 \mathrm{pg}$ were presumed to be diploid whereas those with a genome size ranging from 0.77 to $0.97 \mathrm{pg}$ were presumed to be
Table 2 Clonal diversity of Daphnia tenebrosa summarized for 1981,1987 and 1991

\begin{tabular}{cccc}
\hline & \multicolumn{3}{c}{ Percentage of ponds } \\
\cline { 2 - 4 } $\begin{array}{l}\text { Number of } \\
\text { clones per pond }\end{array}$ & 1981 & 1987 & 1991 \\
\hline 1 & 33 & 15 & 39 \\
2 & 18 & 23 & 19 \\
3 & 27 & 19 & 16 \\
4 & 13 & 15 & 9 \\
5 & 5 & 8 & 7 \\
6 & 3 & 8 & 9 \\
7 & 0 & 0 & 0 \\
8 & 0 & 8 & 0 \\
9 & 0 & 4 & 0 \\
Mean $( \pm$ SE) & $2.6( \pm 0.17)$ & $3.6( \pm 0.44)$ & $2.6( \pm 0.24)$ \\
$*$ Mean $( \pm$ SE) & $2.9( \pm 0.33)$ & $3.6( \pm 0.44)$ & $2.9( \pm 0.33)$ \\
\hline
\end{tabular}

*For 27 ponds sampled in 1981, 1987 and 1991

tetraploids. The UPGMA dendrogram of allozyme divergence (Fig. 5) revealed three clusters among the $D$. tenebrosa clones. However, there was no association between ploidy level or pigmentation and allozyme assemblage. There was also no relationship between genome size and heterozygosity $\left(t_{16}=-0.48, P>0.05\right.$; Table 3). There was, however, a strong correspondence between allozyme genotypes and ploidy levels. Eight of 10 clones with unbalanced allozyme phenotypes were found to be polyploids whereas seven of eight clones with normal allozyme phenotypes were assigned as diploids.

\section{MtDNA analysis}

The size of the mitochondrial fragment was $2030 \pm 166 \mathrm{bp}$, with no apparent size variation among clones. Three enzymes (DdeI, HaeIII, Sau96I) produced banding patterns that were too complex to be resolved as sites and hence were not included in the analysis. However, the other seven restriction endonucleases produced banding patterns from which restriction sites could be inferred (Appendix I). Fourteen different haplotypes were generated following digestion with these enzymes (Table 4). An UPGMA of these data revealed the presence of two major clusters separated by an estimated sequence divergence of 25 per cent (Fig. 6). Clones of different ploidy level and different pigmentation intensity were found in both clusters, suggesting a polyphyletic origin for both polyploidy and pigmentation in this species. There was no correspondence between allozyme distance and mtDNA divergence among clonal pairs (Pearson's coefficient of correlation $=0.062, R^{2}=0.004, P>0.05$ ). 
(a)

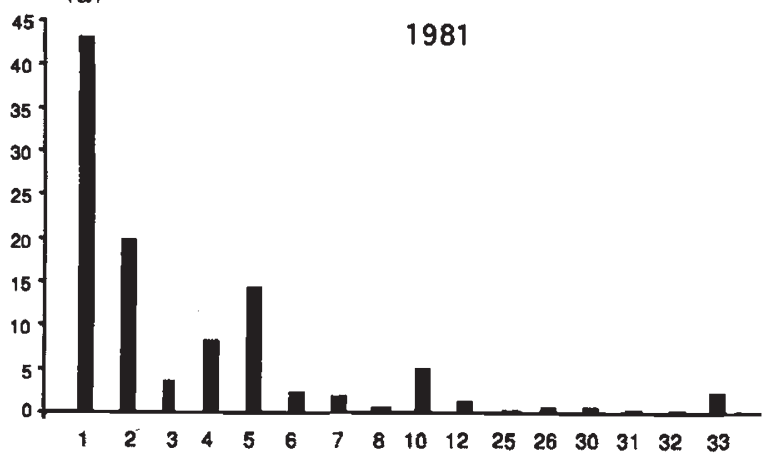

(b)
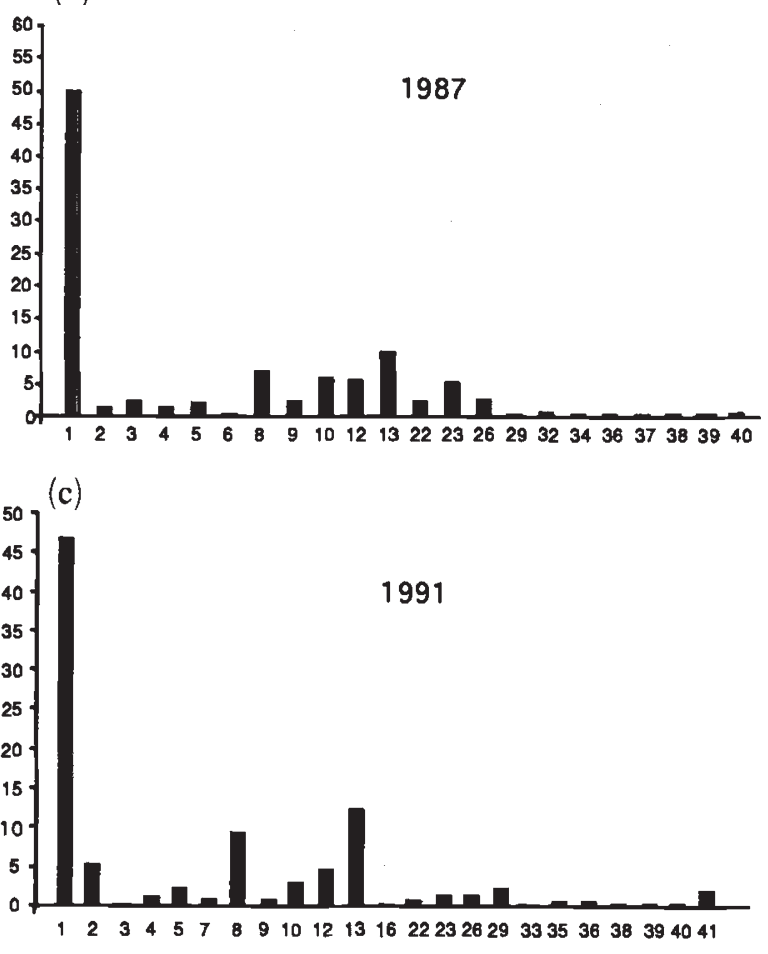

Clone

Fig. 2 Percentage abundances of clones of Daphnia tenebrosa at Churchill in 1981 (a), 1987 (b), and 1991 (c).

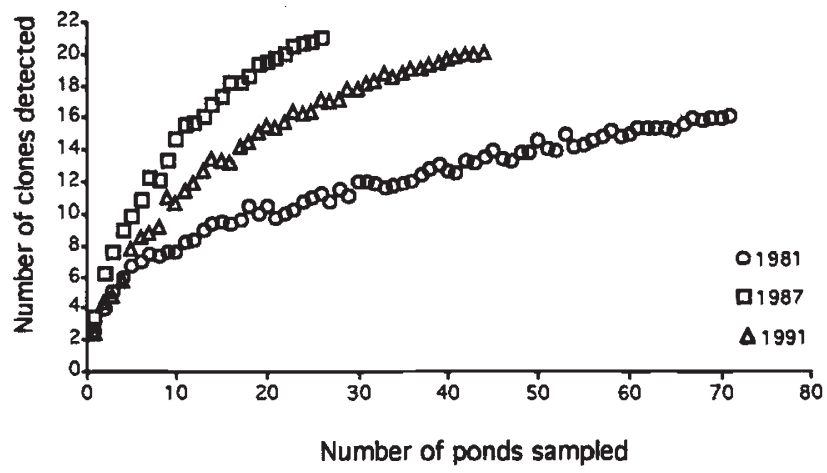

Fig. 3 Relationships between the number of clones of Daphnia tenebrosa detected and the number of ponds sampled for 1981, 1987 and 1991.

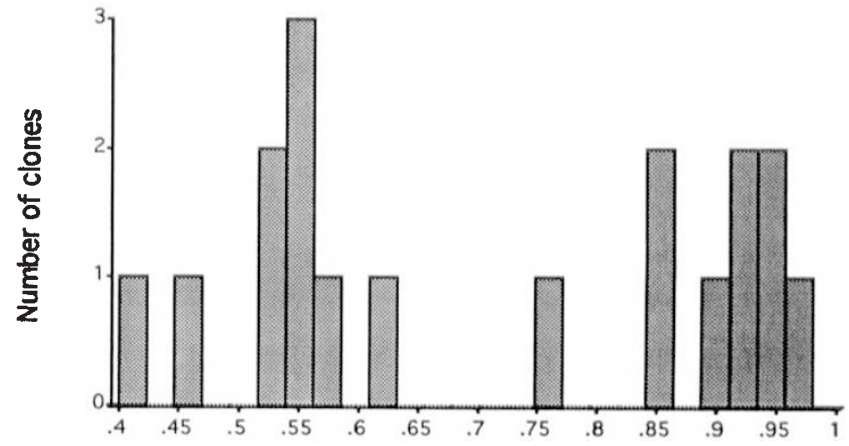

Genome size (pg)

Fig. 4 Frequency histogram of mean genome size (pg) estimates for 18 clones of Daphnia tenebrosa.

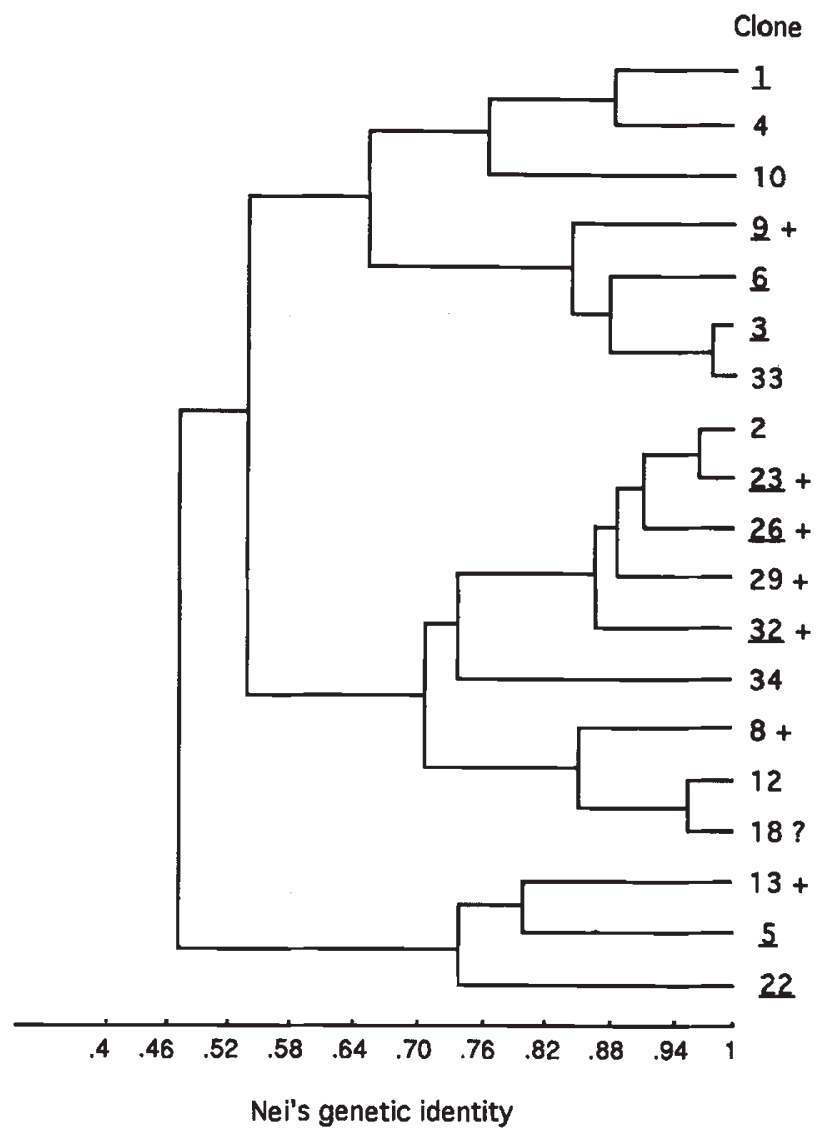

Fig. 5 UPGMA dendrogram of Nei's (1978) genetic identity based on divergence at five loci for 19 clones of Daphnia tenebrosa. Polyploid clones are underlined. ? Refers to clones for which ploidy levels have not yet been assigned.

Pigmented clones are marked + .

However, some allozyme alleles (e.g. PGI-3 and PGM1) were only found in clones belonging to the first mtDNA cluster whereas another allele $(P G M-5)$ was only found in clones in the second mtDNA cluster. 
Table 3 Proportion of polymorphic loci $(P)$, mean genome size (pg) and presumptive ploidy levels for 18 clones of Daphnia tenebrosa

\begin{tabular}{rrrc}
\hline & & Genome size & $\begin{array}{c}\text { Presumptive } \\
\text { ploidy level }\end{array}$ \\
\hline 1 & $P$ & $0.77 \pm 0.12$ & $4 n$ \\
2 & 40 & $0.45 \pm 0.02$ & $2 n$ \\
3 & 0 & $0.92 \pm 0.06$ & $4 n$ \\
4 & 40 & $0.55 \pm 0.10$ & $2 n$ \\
5 & 0 & $0.86 \pm 0.12$ & $4 n$ \\
6 & 40 & $0.94 \pm 0.07$ & $4 n$ \\
8 & 20 & $0.57 \pm 0.07$ & $2 n$ \\
9 & 40 & $0.94 \pm 0.06$ & $4 n$ \\
10 & 40 & $0.61 \pm 0.11$ & $2 n$ \\
12 & 40 & $0.52 \pm 0.08$ & $2 n$ \\
13 & 40 & $0.55 \pm 0.08$ & $4 n$ \\
22 & 80 & $0.85 \pm 0.05$ & $4 n$ \\
23 & 60 & $0.97 \pm 0.04$ & $4 n$ \\
26 & 20 & $0.90 \pm 0.09$ & $2 n$ \\
29 & 40 & $0.40 \pm 0.03$ & $4 n$ \\
32 & 40 & $0.93 \pm 0.11$ & $2 n$ \\
33 & 40 & $0.52 \pm 0.17$ & $2 n$ \\
34 & 20 & $0.56 \pm 0.03$ & \\
\hline
\end{tabular}

Table 4 Haplotypes for 16 allozymic clones of Daphnia tenebrosa generated by digestion with seven restriction endonucleases

\begin{tabular}{cccccccc}
\hline & \multicolumn{7}{c}{ Restriction enzymes } \\
$\begin{array}{c}\text { Allozymic } \\
\text { clone }\end{array}$ & RsaI & Cfol & MboI & HpaII & Hinfl & TaqI & AluI \\
\cline { 2 - 7 } 1 & C & C & C & A & B & F & B \\
2 & C & C & C & A & B & E & B \\
4 & B & C & C & A & B & E & B \\
6 & B & B & C & B & C & C & A \\
8 & C & C & C & A & A & B & B \\
9 & B & B & C & B & A & A & C \\
10 & B & E & C & B & C & C & A \\
12 & B & D & C & B & C & A & A \\
13 & C & C & A & A & B & F & B \\
18 & C & C & C & A & B & B & B \\
23 & B & D & C & B & A & A & A \\
24 & A & A & A & A & B & A & A \\
26 & B & D & C & B & A & D & A \\
29 & B & D & C & B & A & C & A \\
32 & B & B & B & B & A & A & A \\
40 & B & D & C & B & A & D & A \\
\hline
\end{tabular}

\section{Discussion}

This study has established that populations of $D$. tenebrosa from the Churchill area possess high clonal diversity. Thirty-two clones were detected over the three sampling years based on analysis at just five
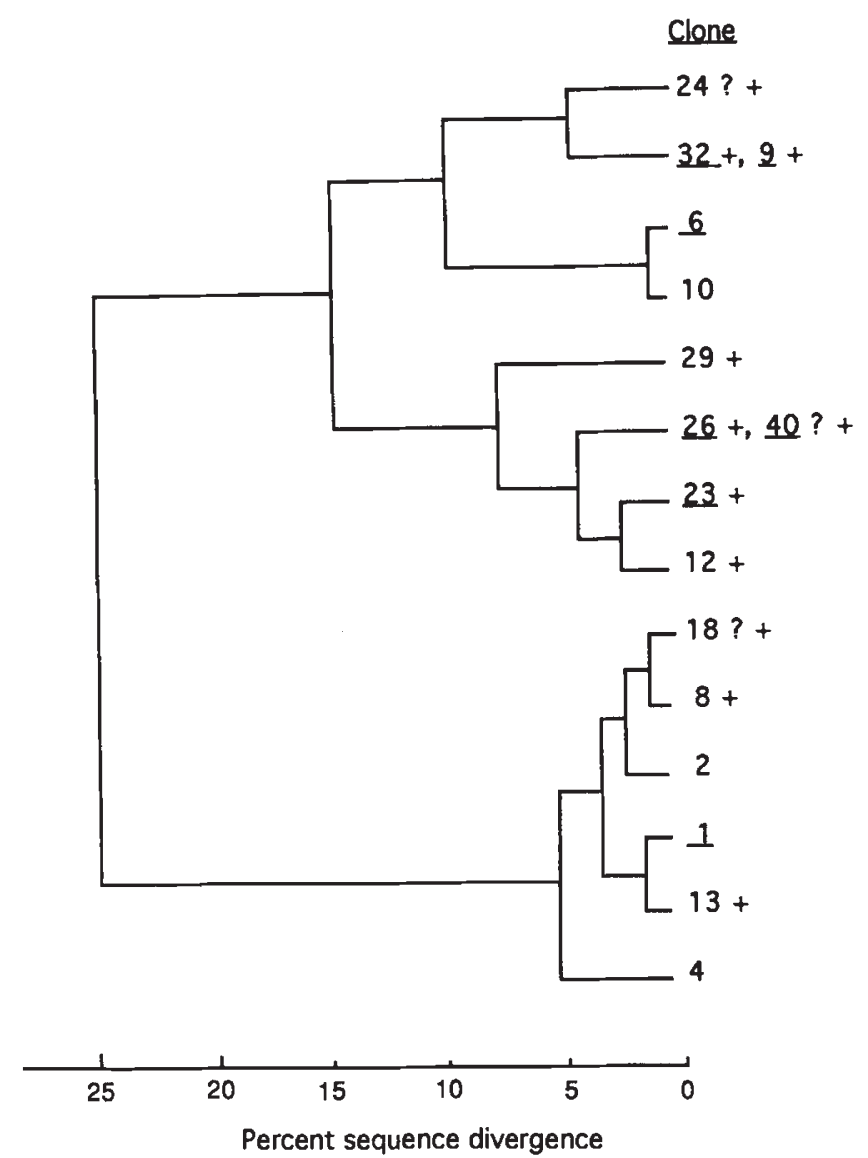

Fig. 6 UPGMA dendrogram of 16 Daphnia tenebrosa clones based on sequence divergence at the ND4-ND5 mitochondrial region. Polyploid clones are underlined. ? Refers to clones for which ploidy levels have not yet been assigned. Pigmented clones are marked + .

variable enzyme loci. Clonal diversity in $D$. tenebrosa appears higher than that in other taxa of the pulex complex at the same site, with an average of 2.9 clones per pond compared with 1.7 clones for $D$. pulex and 1.5 for $D$. middendorffiana (Weider \& Hebert, 1987a; Wilson \& Hebert, 1992). Recent studies (Hobaek et al., 1993; Ward et al., 1994) have shown that populations of $D$. pulex from Eurasia have a similarly low level of clonal diversity ( 1.5 and 1.7 clones per pond). Higher clonal diversity estimates have however been reported for $D$. middendorffiana from a high-arctic site $(4.5$ clones per pond) and for $D$. pulex from a temperate zone region (2-4 clones per pond) (Hebert \& Crease, 1983; Hebert et al., 1989). The high levels of clonal diversity in $D$. tenebrosa from Churchill may be linked to the larger size of their habitats, which have on average 100 times the surface area of ponds occupied by $D$. middendorffiana and $D$. pulex in the same region.

Clonal frequencies were relatively stable in the 27 ponds sampled over the 10-year interval, suggesting that an equilibrium has been reached. Populations of $D$. 
tenebrosa were typically dominated by a few widespread clones and several rare ones, a clonal structure typical of many aquatic invertebrate populations (Weider \& Hebert, 1987a; Zhao \& King, 1989; Browne, 1992; Wilson \& Hebert, 1992). Reasons for the differential distribution of the $D$. tenebrosa clones are not clear. Common clones might be widely distributed because they have broadly adapted genotypes or because their preferred habitat type is prevalent. A study on $D$. pulex from Churchill found that individual clones were narrowly adapted to specific environmental conditions (salinity, predation regime) with common clones adapted to abundant habitat types (Wilson \& Hebert, 1992). Similarly, D. middendorffiana clones from Churchill show distributional patterns linked to their specific physiological tolerances to salinity (Weider \& Hebert, 1987b).

The genome size studies showed that clones of $D$. tenebrosa could be assigned to two ploidy groups: one corresponding to diploids and a second which appears to include tetraploids as the average genome size value was 1.7 times the diploid value (range 1.48-1.86). Smaller than expected genome sizes in tetraploids have also been noted in clones of D. pulex (Beaton \& Hebert, 1988), suggesting that chromosome loss has occurred following polyploidization. Chromosome analyses are needed to verify if clones with the lowest genome size values are triploids or if only tetraploids are present within this assemblage.

Unbalanced staining activity was a good indicator of polyploidy. Eight of ten clones with unbalanced staining activity at one or several loci were polyploids whereas seven of eight clones with normal electrophoretic phenotypes were diploid. It is noteworthy that the diploid genome size $(0.53 \mathrm{pg})$ of $D$. tenebrosa is 70 per cent bigger than that of $D$. pulex, although both species have 24 chromosomes (Beaton \& Hebert, 1994). It may be significant that $D$. tenebrosa, which appears to have the largest genome size of all Daphnia species (Beaton \& Hebert, 1994), is found only at arctic sites. A correlation between large genome size and capacity for growth at low temperature has been found in plants (Thompson, 1990), suggesting that large genomes may be advantageous at low temperatures.

Based on their morphological and allozymical similarity to diploids, polyploid clones of $D$. tenebrosa should be characterized as autopolyploids. However, the high mitochondrial divergence between clones of this species suggests that these clones have an allopolyploid origin. Indeed, the amount of genetic divergence among clones of $D$. tenebrosa is as high as that between $D$. pulex and D. pulicaria, which are putative parents for the allopolyploid clones of $D$. middendorffiana (Dufresne \& Hebert, 1994). The hybridization of longisolated populations of $D$. tenebrosa could explain the high genetic divergence within this species. For example, as $D$. tenebrosa occurs in both Asia and North America, it is possible that the divergent mitochondrial groups reflect diversity that once resided on different continents. Based on this explanation, the admixture of diploid and polyploid clones in both mitochondrial groups might reflect the results of reciprocal hybridization events between the genetically divergent isolates of this taxon. The lack of concordance beween allozyme and mtDNA data further supports the conclusion that both asexuality and polyploidy have a polyphyletic origin in this group.

Although extremely rare or absent in animals, autopolyploidy has been suggested to occur in several plant taxa (Soltis \& Soltis, 1993). Autopolyploids are typically recognized based on morphological and allozymic resemblances to diploids, by the presence of multivalents at meiosis, and by tetrasomic inheritance patterns (Stebbins, 1947). However, these criteria are not sufficiently stringent to rule out the misclassification of allopolyploids. For example, when closely related taxa hybridize, their chromosomes may possess enough homology to form multivalents at meiosis. Furthermore, many cases of autopolyploidy in plants have been classified solely on the basis of allozyme analyses (Soltis \& Soltis, 1993), although evidence now suggests that such analysis can lead to misclassification of taxa that arose through hybridization as autopolyploids. For example, Dufresne \& Hebert (1994) have found a case of cryptic allopolyploidy in Daphnia such that a clone possessed the mtDNA of one species and the nuclear genome of another species. The results of the present study further emphasize the importance of joint analyses of nuclear and cytoplasmic genomes in an effort to infer the mode of origin of polyploidy.

\section{Acknowledgments}

This research was supported by a FCAR scholarship and DINA Northen Training grants to F. D., as well as by a research grant from NSERC to P. D. N. H. Many people collaborated in this long-term study. N. Baby carried out most of the genome size analyses, R. Barrette helped with the electrophoresis, while P. Gajda and M. Cornish provided assistance in the field. We thank M. Beaton for helpful comments on earlier drafts of the manuscript.

\section{References}

BEATON, M. J. AND HEBERT, P. D. N. 1988. Geographical parthenogenesis and polyploidy in Daphnia pulex. Am. Nat., 132, $837-845$.

BEATON, M. J. AND HEBERT, P. D. N. 1989. Miniature genomes and endopolyploidy in cladoceran crustaceans. Genome, 32, 1048-1053. 
BEATON, M. J. AND HEBERT, P. D. N. 1994. Variation in chromosome numbers in Daphnia. (Crustacea, Cladocera) Hereditas, 120, 275-279.

BELL, G. 1982. The Masterpiece of Nature: the Evolution and Genetics of Sexuality. University of California Press, Berkeley.

BIERZYCHUDEK, P. 1985. Patterns in plant parthenogenesis. Experientia, 41, 1255-1263.

BRooks, J. L. 1957. The systematics of North American Daphnia. Mem. Conn. Acad. Arts Sci., 13, 1-180.

BRowne, R. A. 1992. Population genetics and ecology of Artemia: insights into parthenogenetic reproduction. Trends Ecol. Evol., 7, 232-237.

CHRISTENSEN, B., NOER, H. AND THEISEN, B. F. 1988. Differential responses to humidity and soil type among clones of triploid parthenogenetic Trichoniscus pusillus (Isopoda, Crustacea). Hereditas, 108, 213-217.

CREASE, T. J., STANTON, D. J. AND HEBERT, P. D. N. 1989. Polyphyletic origins of asexuality in Daphnia pulex . II. Mitochondrial DNA variation. Evolution, 43, 1016-1026.

DUFRESNE, F. AND HEBERT, P. D. N. 1994. Hybridization and origins of polyploidy. Proc. R. Soc. B, 258, 141-146.

ELLSTRAND, N. C. AND ROSE M. L. 1987. Patterns of clonal diversity in clonal plant species. Am. J. Bot., 74, 123-131.

FELSENSTEIN, J. 1993. PHYLIP (Phylogeny Inference Package). Version 3.5c. Department of Genetics, University of Washington, Seattle, U.S.A.

HEBERT, P. D. N. 1987. Genotypic characteristics of the Cladocera. Hydrobiologia, 145, 183-293.

HEBERT, P. D. N. AND BEATON, M. J. 1989. Methodologies for Allozyme Analyses Using Cellulose Acetate Electrophoresis. Helena Laboratories, Beaumont, TX.

HEBERT, P. D. N., BEATON, M. J., SCHWARTZ, S. S. AND STANTON, D. J. 1989. Polyphyletic origins of asexuality in Daphnia pulex. I. Breeding-system variation and levels of clonal diversity. Evolution, 43, 1004-1015.

HEBERT, P. D. N. AND CREASE, T. 1983. Clonal diversity in populations of Daphnia pulex reproducing by obligate parthenogenesis. Heredity, 51, 353-369.

HEBERT, P. D. N. AND McWALTER, D. B. 1983. Cuticular pigmentation in arctic Daphnia: adaptive diversification of asexual lineages? Am. Nat., 122, 286-291.

HEBERT, P. D. N., SCHWARTZ, S. S., WARD, R. D. AND FINSTON, T. L. 1993. Macrogeographic patterns of breeding system diversity in the Daphnia pulex group. I. Breeding systems of Canadian populations. Heredity, 70, 148-161.

HOBAEK, A., WEIDER, L. J. AND WOLF, H. G. 1993. Ecological genetics of Norwegian Daphnia. III. Clonal richness in an Arctic apomictic complex. Heredity, 71, 323-330.

KREBS, C. J. 1989. Ecological Methodology. Harper and Row, New York.

LEWIS, w. H. 1980. Polyploidy: Biological Relevance. Plenum Press, New York.

McElROY, D., MORAN, P., BERMINGHAM, E. AND KORNFIELD, I. 1991. The Restriction Enzyme Analysis Package. Version 4. University of Maine, Orono, ME.

MOGIE, M. 1986. On the relationship between asexual reproduction and polyploidy. J. Theor. Biol., 122, 493-498.
NEI, M. 1978. Estimation of average heterozygosity and genetic distance from a small number of individuals. Genetics, 89, 583-590.

NEI, M. AND TAJIMA, F. 1983. Maximum likelihood estimates of the number of nucleotide substitutions from restriction sites data. Genetics, 105, 207-217.

PARKER, E. D. 1979. Ecological implications of clonal diversity in parthenogenetic morphospecies. Am. Zool., 19, 753-762.

SNEATH, P. H. A. AND SOKAL, R. R. 1973. Numerical Taxonomy, the Principles and Practice of Numerical Classification. W. H. Freeman, San Francisco, CA.

Soltis, D. E. AND SolTIS, P. S. 1993. Molecular data and the dynamic nature of polyploidy. Crit. Rev. Plant. Sci., 12, 243-273.

STANTON, D. J. 1988. Evolution of Asexuality in D. pulex: Implications of Mitochondrial DNA Analysis. Ph. D. Thesis, University of Windsor, Canada.

STEBrins, G. L. 1947. Types of polyploids: their classification and significance. Adv. Genet., 1, 403-429.

SWOFFORD, D. L. AND SELANDER, R. B. 1989. BIOSYS-1. A computer program for the analysis of allelic variation in population genetics and biochemical systematics. Illinois Natural History Survey, Champaign.

TAYLOR, D. J. AND HEBERT, P. D. N. 1993. Habitat-dependent hybrid parentage and differential introgression between neighboringly sympatric Daphnia species. Proc. Natl. Acad. Sci. U.S.A, 90, 7079-7083.

THOMPSON, K. 1990. Genome size, seed size and germination temperature in herbaceous angiosperms. Evol. Trends Plants, 4, 113-116.

VAN RAAY, T. J. AND CREASE, T. J. 1995. Mitochondrial DNA diversity in an apomictic Daphnia complex from the Canadian high arctic. Mol. Ecol. (in press).

WARD, R. D., BICKERTON, M. A., FINSTON, T. AND HEBERT, P. D. N. 1994. Geographical cline in breeding systems and ploidy levels in European populations of Daphnia pulex. Heredity, 73, 532-543.

WEIDER, L. J., BEATON, M. J. AND HEBERT, P. D. N. 1987. Clonal diversity in high-arctic populations of Daphnia pulex, a polyploid apomictic complex. Evolution, 41, 1335-1346.

WEIDER, L. J. AND HEBERT, P. D. N. 1987a. Microgeographic genetic heterogeneity of melanic Daphnia pulex at a lowArctic site. Heredity, 58, 391-399.

WEIDER, L. J. AND HEBERT, P. D. N. 1987b. Ecological and physiological differentiation among low-arctic clones of Daphnia pulex. Ecology, 68, 188-198.

WEIDER, L. J. AND HOBAEK, A. 1994. Molecular biogeography of clonal lineages in a high-arctic Daphnia pulex complex. Mol. Ecol., 3, 497-506.

WILSON, C. C. AND HEBERT, P. D. N. 1992. The maintenance of taxon diversity in an asexual assemblage: an experimental analysis. Ecology, 73, 1462-1472.

ZHAO, Y. AND KING, C. E. 1989. Ecological genetics of the rotifer Brachionus plicatilis in Soda Lake, Nevada, USA. Hydrobiologia, 185, 175-181.

ZHANG, L. AND LEFCORT, H. 1992. The effects of ploidy level on thermal distributions of brine shrimp Artemia parthenogenetica and its ecological implications. Heredity, 66, 445-452.

(c) The Genetical Society of Great Britain, Heredity, 75, 45-53. 
Appendix I. Estimates of fragment sizes (in base pairs) obtained following digestions of amplified mtDNA with seven restriction endonucleases

\begin{tabular}{|c|c|c|c|c|c|c|c|}
\hline \multirow[b]{2}{*}{ Enzymes } & \multicolumn{7}{|c|}{ Fragment } \\
\hline & A & B & C & D & $\mathrm{E}$ & $\mathrm{F}$ & $\mathrm{G}$ \\
\hline \multirow[t]{5}{*}{$R s a \mathrm{I}$} & 720 & 850 & 700 & & & & \\
\hline & 700 & 700 & 580 & & & & \\
\hline & 360 & 360 & 500 & & & & \\
\hline & 200 & 200 & 300 & & & & \\
\hline & 100 & & & & & & \\
\hline \multirow[t]{4}{*}{ CfoI } & 1000 & 950 & 1100 & 1100 & 850 & & \\
\hline & 850 & 850 & 800 & 900 & 700 & & \\
\hline & 250 & 250 & 150 & & 250 & & \\
\hline & & 100 & & & 150 & & \\
\hline \multirow[t]{6}{*}{$M b o I$} & 580 & 1100 & 1100 & & & & \\
\hline & 520 & 500 & 400 & & & & \\
\hline & 400 & 300 & 300 & & & & \\
\hline & 300 & 150 & 150 & & & & \\
\hline & 150 & & 120 & & & & \\
\hline & 120 & & & & & & \\
\hline \multirow[t]{5}{*}{ HpaII } & 600 & 800 & & & & & \\
\hline & 550 & 600 & & & & & \\
\hline & 380 & 380 & & & & & \\
\hline & 250 & 250 & & & & & \\
\hline & 240 & & & & & & \\
\hline \multirow{8}{*}{ HinfI } & 820 & 820 & 820 & & & & \\
\hline & 350 & 650 & 350 & & & & \\
\hline & 300 & 250 & 250 & & & & \\
\hline & 250 & 150 & 170 & & & & \\
\hline & 150 & 120 & 150 & & & & \\
\hline & 120 & 80 & 130 & & & & \\
\hline & 80 & & 120 & & & & \\
\hline & & & 80 & & & & \\
\hline \multirow[t]{8}{*}{ TaqI } & 800 & 700 & 700 & 800 & 700 & 700 & \\
\hline & 400 & 400 & 400 & 520 & 520 & 400 & \\
\hline & 275 & 275 & 275 & 400 & 400 & 275 & \\
\hline & 270 & 240 & 250 & 180 & 180 & 270 & \\
\hline & 180 & 180 & 180 & 160 & 160 & 180 & \\
\hline & 160 & 160 & 160 & 120 & 120 & 160 & \\
\hline & 120 & 120 & 120 & & 100 & 120 & \\
\hline & & 100 & 100 & & & 100 & \\
\hline \multirow[t]{6}{*}{ AluI } & 1200 & 600 & 700 & & & & \\
\hline & 200 & 400 & 500 & & & & \\
\hline & 170 & 200 & 200 & & & & \\
\hline & 120 & 170 & 170 & & & & \\
\hline & 90 & 120 & 120 & & & & \\
\hline & & 90 & 90 & & & & \\
\hline
\end{tabular}

